\begin{tabular}{|c|c|c|}
\hline UFG & 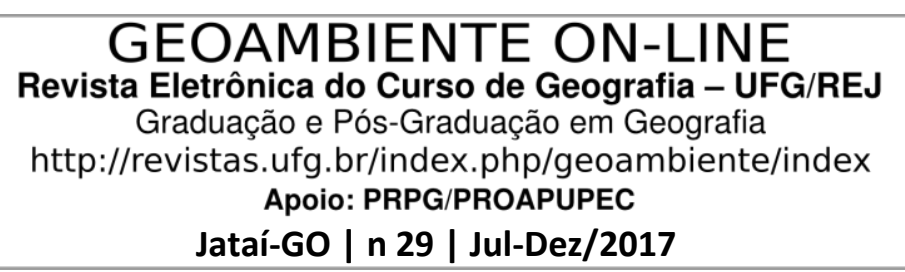 & $\begin{array}{l}\overbrace{\text { OGEO }} \\
\text { ISSN } 1679-9860 \\
\text { ISAMBIENTE }\end{array}$ \\
\hline
\end{tabular}

\title{
DIAGNÓSTICO AMBIENTAL E PROPOSIÇÃO DE USO DE SAF PARA ÁREA DE PASTAGEM DEGRADADA
}

Bianca Pietsch Cunha Bendito ${ }^{1}$; Patrícia Aparecida de Souza ${ }^{2}$; Mayanne Alves Pereira ${ }^{1}$; Douglas Santos Gonçalves ${ }^{1}$

(1 - Universidade Federal do Tocantins, Mestranda em Ciências Florestais e Ambientais, biancapcb.engamb@gmail.com; mayanneap_22@hotmail.com; goncalvesds@hotmail.com; 2 - Universidade Federal do Tocantins, Docente do Programa Ciências Florestais e Ambientais, patriciaapsouza@uft.edu.br)

RESUMO: No Brasil, há milhões de áreas de pastagem em algum estágio de degradação. Com o intuito de reverter este quadro, o Plano Setorial de Agricultura de Baixa Emissão de Carbono $(\mathrm{ABC})$ estimula a adoção de técnicas de recuperação e de utilização produtiva de pastagens degradadas. O Plano também visa tornar essas atividades economicamente mais atrativas; visa prevenir a degradação de novas áreas de pastagens e aumentar a produtividade. O Sistema Agroflorestal (SAF) está entre os tipos de programas que compõem o Plano Setorial. O presente trabalho objetivou diagnosticar a degradação de uma área de pastagem no Município de Gurupi, TO, através da avaliação qualitativa e quantitativa, e indicar modelos de SAFs para aplicação na área. Os impactos descritos pelo "Check-list" foram: morte da pastagem, presença de plantas invasoras, compactação do solo e erosão laminar. A análise qualitativa dos impactos demonstrou o caráter reversível dos impactos, confirmado pela análise quantitativa. Esta revelou que a área se encontra em estado de degradação severa, necessitando de intervenção para reverter o quadro. De acordo com a literatura, os SAFs, que mesclam espécies arbóreas (eucalipto, mogno e cedro) com espécies não arbóreas, são modelos que podem gerar maiores ganhos econômicos e ambientais.

Palavras-chave: diagnóstico ambiental, pastagem, sistema agroflorestal, plano ABC

\section{ENVIRONMENTAL DIAGNOSIS AND PROPOSED USE OF SAF FOR DEGRADED PASTURE AREA.}

ABSTRACT: In Brazil there are millions of pasture areas at some stage of degradation. In order to reverse this situation, the Sectorial Plan for Low Carbon Emission (ABC) stimulates

Artigo recebido para publicação em 30 de julho de 2016

Artigo aprovado para publicação em 20 de Dezembro de 2017 


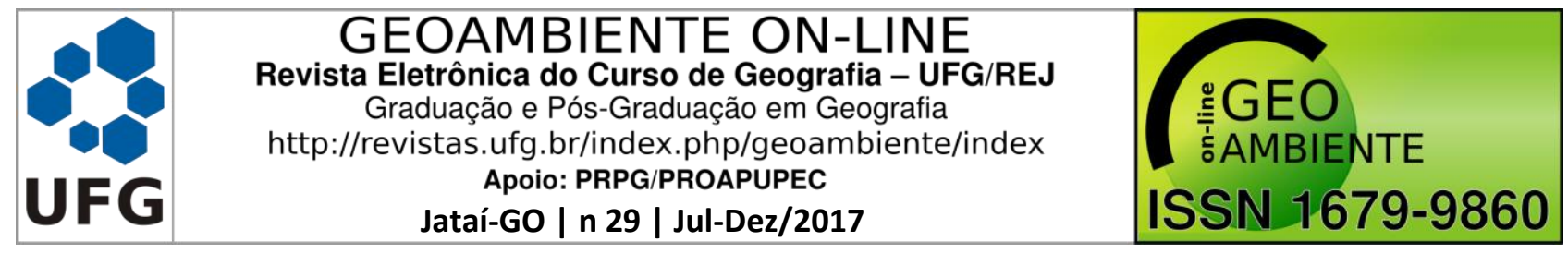

the adoption of recovery techniques and of productive use of degraded pastures. The Sectorial Plan also aims to make these activities economically more attractive; aims to prevent degradation of new pasture areas and to increase productivity. The Agroforestry System (SAF) is among the types of programs that make up the Sectorial Plan. The present work aimed to diagnose the pasture area degradation in the municipality of Gurupi, TO, through qualitative and quantitative evaluation, and aimed to indicate SAF models for application in the area. The impacts described by "Checklist" were: pasture death, presence of invasive plants, soil compaction, and laminar erosion. The impact qualitative analysis demonstrated the reversible nature of the impacts, which was confirmed by the quantitative analysis. The latter revealed that the area is in a state of severe degradation, requiring intervention to reverse this condition. According to the literature, the SFAs that mix arboreal species (eucalypt, mahogany and cedar) with non-tree species, are the models that can generate greater economic and environmental gains.

Keywords: environmental diagnosis, pasture, agroforestry system, ABC plan.

\section{DIAGNÓSTICO AMBIENTAL Y PROPUESTA DE USO DE SAF PARA LA ZONA DE PASTOS DEGRADADOS.}

RESUMEN:Brasil tiene millones de zonas de pastizales en alguna etapa de la degradación. Para revertir esta situación, el Plan Sectorial de agricultura de baja emisión de carbono (ABC) estimula el uso de técnicas de recuperación y utilización productiva de pastizales degradados. Se pretende hacer estas actividades económicamente más atractivas; prevenir la degradación de las nuevas áreas de pastizales y aumentar la productividad. Entre los tipos de programas que integran el Plan se encuentra el sistema agroforestal (SAF). El presente trabajo tiene como objetivo diagnosticar la degradación de una zona de pastizales en el municipio de Gurupi, a través de análisis cualitativo y cuantitativo, así determinar los modelos de SAF más indicados para en el área de aplicación. Los impactos descritos por "Check-list" fueron: la muerte de los pastizales, presencia de plantas invasoras, compactación del suelo y la erosión laminar. El análisis cualitativo de los impactos demostró el carácter reversible de los impactos, confirmado por el análisis cuantitativo, el cual confirmo que el área de estudio se encuentra en un estado de degradación fuerte, que requiere una intervención, para revertir los daños. Según la literatura, los SAFA’s que mezclan especies de árboles (eucalipto, caoba y 


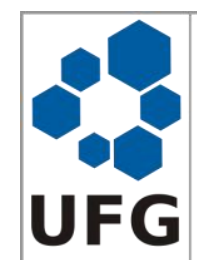

\section{GEOAMBIENTE ON-LINE Revista Eletrônica do Curso de Geografia - UFG/REJ \\ Graduação e Pós-Graduação em Geografia \\ http://revistas.ufg.br/index.php/geoambiente/index Apoio: PRPG/PROAPUPEC \\ Jataí-GO | n 29 | Jul-Dez/2017}

:GEO ¿̇AMBIENTE ISSN 1679-9860

cedro) con especies no arbóreas son un modelo que puede generar mayores beneficios económicos y ambientales.

\section{INTRODUÇÃO}

O termo "pastagem degradada" geralmente está relacionado com acentuada diminuição da produtividade agrícola, que seria esperada para determinada área, podendo ou não ter perdido a capacidade de manter a produtividade do ponto de vista biológico (acumular carbono). Para Macedo (1993), Macedo e Zimmer (1993) é um processo evolutivo de perda de vigor, de produtividade, da capacidade de recuperação natural das pastagens para sustentar os níveis de produção e qualidade exigidos pelos animais.

São vários os fatores que podem levar à degradação das pastagens, entre eles, a escolha incorreta da espécie forrageira, a má formação inicial, a falta de adubação de manutenção e o manejo inadequado da pastagem. Além desses fatores, as queimadas também podem influenciar negativamente as pastagens, pois causam perdas de nutrientes por volatilização; o escorrimento superficial e a lixiviação, e expõem o solo ao impacto direto das gotas das chuvas, acelerando os processos erosivos (PERON e EVANGELISTA, 2004).

O Brasil tem aproximadamente 180 milhões de hectares de pastagens, dos quais mais da metade encontra-se em algum estágio de degradação, sendo que grande parte está estágio avançado (ZEBU,2015). A caracterização de determinada pastagem como degradada ou em degradação pode estar relacionada a aspectos bem particulares, que dizem respeito à região ou nível tecnológico da propriedade rural, isto é, pode se referir à produtividade que se consideraria ideal para aquela região e pastagem em particular.Uma pastagem considerada degradada em determinado local pode ser considerada ainda produtiva em outro, sendo necessária uma avaliação no local, através do diagnóstico ambiental (DIAS-FILHO, 2011).

Com o intuito de reverter esse quadro, o governo brasileiro criou o Plano Setorial de Agricultura de Baixa Emissão de Carbono (ABC) (BRASIL, 2012)com finalidade de responder aos compromissos de redução de emissão de gases de efeito estufa (GEE) no setor agropecuário assumido pelo país. E visa estimular a adoção de variedades apropriadas de forrageiras; enriquecer as pastagens tornando, a recuperação e utilização produtiva de pastagens degradadas, atividades economicamente mais atrativas; prevenir a degradação de novas áreas de pastagens e aumentar a produtividade. O Plano é composto por sete programas, seis deles referentes às tecnologias de mitigação no qual está incluso o programa referente aos Sistemas Agroflorestais (SAFs). 


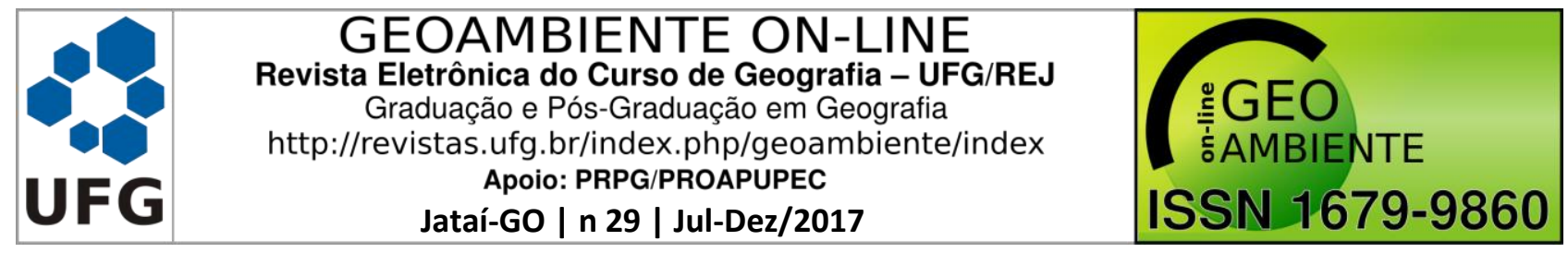

As vantagens da recuperação de pastagens degradadas são muitas, entre estas se citam: a redução de custos e de riscos de pragas, o aumento da eficiência no uso da mão de obra e dos recursos de produção e de energia, melhoria nas propriedades físicas, químicas e biológicas(RODRIGUES, 2014).

Para que o produtor possa se beneficiar da recuperação de áreas degradadas, é necessário que se faça um diagnóstico ambiental da área para se constatar o grau de perturbação ou de degradação e a partir disso ser orientado para a realização de análises mais profundas e determinação da melhor técnica ambiental e economicamente viável para a recuperação.

Dentre as principais técnicas usadas pelo programa $\mathrm{ABC}$, estão os sistemas agroflorestais (SAFs) que consistem em consórcios de culturas agrícolas com espécies arbóreas que podem ser utilizados para restaurar florestas e recuperar áreas degradadas. A tecnologia ameniza limitações do terreno, minimiza riscos de degradação inerentes à atividade agrícola e otimiza a produtividade a ser obtida. Esse sistema além de produtivo, e pode recuperar áreas degradadas, devido às melhorias que promove nas condições do solo e pelas interações positivas entre seus componentes(TORRES, 2015).

Estudos que utilizem o diagnóstico ambiental para a avaliação de pastagens degradadas para a escolha técnica e métodos de recuperação,se fazem necessários, assim como indicações de recuperação com a viabilização dos SAFs.

Diante disso, o presente estudo objetivou diagnosticar a degradação de uma área de pastagem no Município de Gurupi, através de avaliação qualitativa e quantitativa e denotar modelos de SAFs, para auxiliar na implantação de ações de recuperação.

\section{MATERIAIS E MÉTODOS}

\section{Área de Estudo:}

A área de pastagem objeto de estudo encontra-se na Fazenda Veneza, que corresponde a $30 \%$ da área da propriedade, cerca de 1ha. Essa área pode ser observada na Figura 1, demarcada pelo polígono vermelho.

A propriedade fica a1300 metros da rodovia TO 365 e cerca de $30 \mathrm{Km}$ do município de Gurupi-TO, localizado na região sul do Estado do Tocantins, sob as coordenadas $11^{\circ} 38^{\prime} 16.62^{\prime}$ 'S de latitude e 4848'48.98”'O de longitude (Figura 01). 


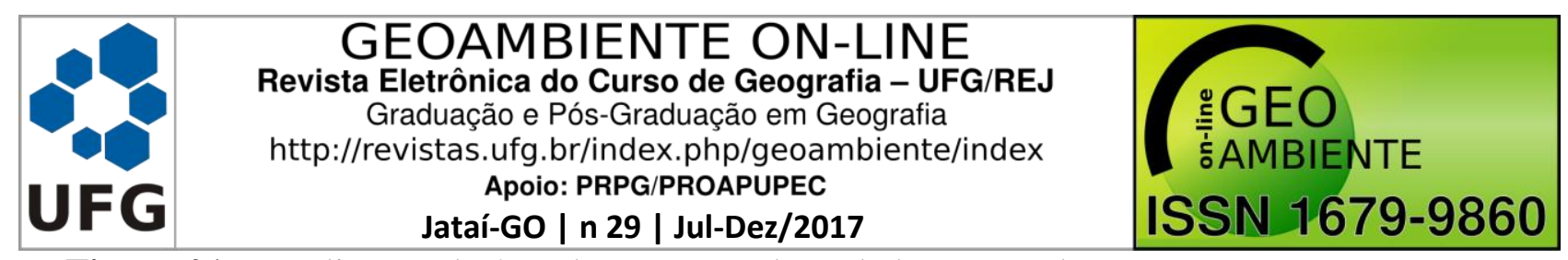

Figura 01: Localização da área de pastagem degradada em estudo.

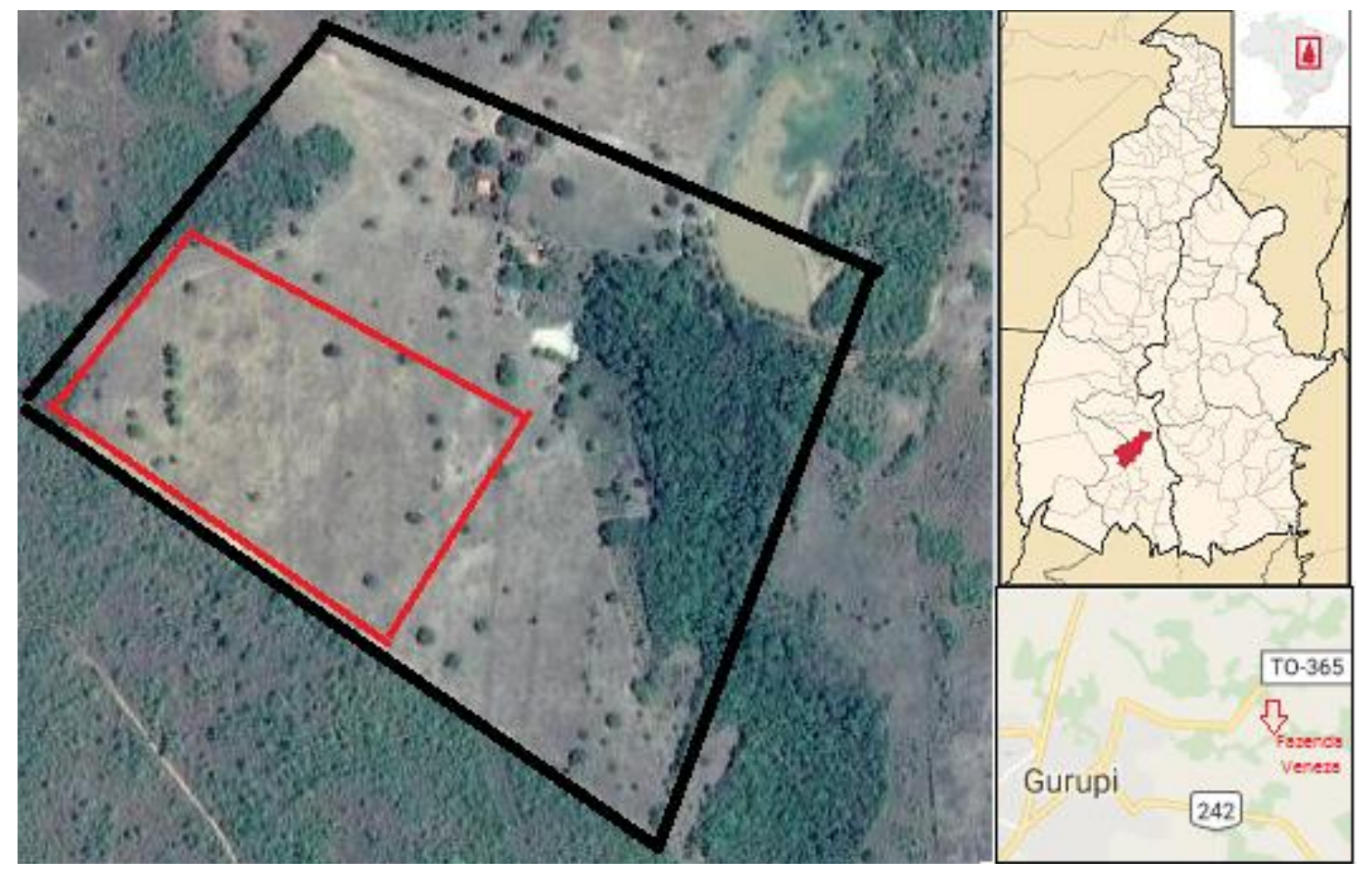

\section{Metodologia:}

Primeiramente realizou-se o diagnóstico ambiental da área, que consistiu na caracterização do local por meio de visita técnica em campo para observação da área, dos fatores ambientais e os possíveis impactos existentes.Através da observação listaram-se os impactos ambientais por meio da metodologia de "Checklist" descritivo, de acordo com Sánchez (2013).

Com base no "Checklist" descritivo os impactos ambientais foram avaliados qualitativamenteatravés da metodologia de "matriz de análise dos impactos" proposta por Leopold et. al. (1971), adaptada por Sánchez (2013) pelos parâmetros estabelecidos pela Resolução CONAMA nº 001/86 (BRASIL, 1986), Tabela 01.

Através do diagnóstico ambiental fez-se a observação in loco da análise quantitativa com base na metodologia de análise do nível de degradação da pastagem, proposta por Nascimento Júnior et. al. (1994). Esta metodologia consiste em observar a área e avaliar visualmente cinco parâmetros: Vigor e qualidade das pastagens (VQ), População de plantas da forrageira (PP), Incidência de plantas daninhas (PD,) Cobertura do solo pela pastagem (CS) e Nível de erosão das áreas (NE). Posteriormente estabeleceram-se notas de um a quatro para cada parâmetro: 1 - bom, 2 - regular, 3 - ruim, 4 - muito ruim. 
Tabela 01: Critérios qualitativos para análise dos impactos ambientais diagnosticados na área.

\begin{tabular}{|c|c|c|}
\hline CRITÉRIO & PARÂMETROS & SIGNIFICADO \\
\hline \multirow[t]{2}{*}{ Ordem } & Direto & Quando o impacto é considerado primário. \\
\hline & Indireto & Quando o impacto é uma reação secundária da ação que está sendo realizada. \\
\hline \multirow[t]{2}{*}{ Plástica } & Reversível & Quando o fator ambiental impactado, pode ser recuperado. \\
\hline & Irreversível & Quando o fator ambiental, não é passível de recuperação. \\
\hline \multirow[t]{2}{*}{ Valor } & Positivo & Quando a ação é benéfica para a melhoria da qualidade ambiental. \\
\hline & Negativo & Quando a ação resulta em dano à qualidade de um fator ambiental. \\
\hline \multirow[t]{3}{*}{ Dinâmica } & Temporário & Quando permanece por um determinado tempo, após a realização da ação. \\
\hline & Permanente & $\begin{array}{l}\text { Quando a ação é executada e os efeitos não cessam de se manifestar em um } \\
\text { determinado horizonte conhecido. }\end{array}$ \\
\hline & Cíclico & O efeito se faz sentir em determinados períodos \\
\hline \multirow[t]{4}{*}{ Tempo } & Imediato & Surge no momento em que a ação está sendo realizada. \\
\hline & Curto Prazo & Surge em curto prazo \\
\hline & Médio Prazo & Quando o efeito se manifesta após certo tempo que a ação foi realizada. \\
\hline & Longo Prazo & Quando o efeito se manifesta depois de muito tempo que a ação foi realizada. \\
\hline \multirow[t]{3}{*}{ Espaço } & Local & Quando a ação afeta apenas o próprio local e suas imediações. \\
\hline & Regional & Quando o efeito se propaga além do local e de suas imediações. \\
\hline & Nacional & oropaga em um grande espaço. \\
\hline
\end{tabular}

Fontes: Leopold et. al. (1971), adaptada por Sánchez (2013); Brasil (1986)

Somando-se a nota de cada parâmetro obteve-se um valor que corresponde ao nível de degradação, (Tabela 02), a avaliação foi realizada individualmente para cada um dos parâmetros.

Tabela 02. Níveis de avaliação dos parâmetros utilizados:

\begin{tabular}{ccccccc}
\hline Somatório & $=5-<8$ & $=8-<11$ & $=11-<14$ & $=14-<17$ & $=17-<=20$ \\
\hline $\begin{array}{c}\text { Nível de degradação das } \\
\text { pastagens(NDP) }\end{array}$ & Ausente & Leve & Moderado & Forte & Muito forte \\
\hline
\end{tabular}

Fonte: Nascimento Júnior et. al. (1994).

Com base nas características da região e da degradação diagnosticada, verificou-se a capacidade de recuperação ou não do local, necessidade ou não de intervenção humana. Posteriormente denotaram-se metodologias de SAF apresentadas na literatura,que apresentaram maior viabilidade para as condições de degradações encontradas na área. 


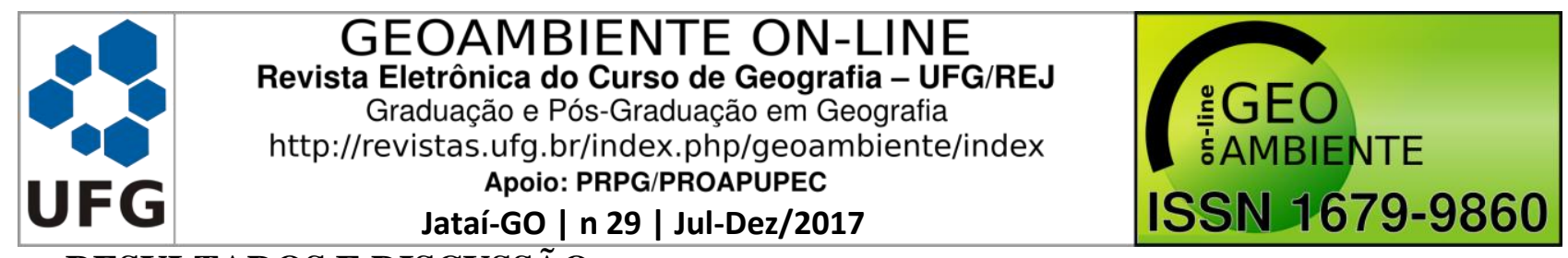

RESULTADOS E DISCUSSÃO

Check-list:

Após a realização do diagnóstico ambiental identificou se 4impactos ambientais na área de pastagem da fazenda Veneza: a morte da pastagem, a presença de plantas invasoras, a compactação do solo e a erosão laminar.

1) Morte da pastagem: durante a visita técnica, observou-se que a pastagem não se apresentava em bom estado e o insucesso desse tipo de vegetação. Em muitos lugares não havia pastagens, e em outros ainda havia, mas não se apresentava com sinais de deficiência.

2) Presença de plantas invasoras: observou-se a presença de espécies que colonizaram o local, vegetação que se diferia da pastagem e da vegetação nativa da região,caracterizada como cerrado. As espécies invasoras apresentam vantagens competitivas e são favorecidas pela ausência de inimigos naturais, têm capacidade de se proliferar e invadir ecossistemas, sejam eles naturais ou antropizados. Este tipo de vegetação é beneficiado pela degradação ambiental e são bem-sucedidas em ambientes e paisagens alteradas(RODOVALHO, 2012).

3) Compactação do solo: observou-se na área a formação de estradas para acesso a alguns locais da propriedade, ocorrendo a compactação de parte do solo da área devido ao trânsito de veículos. De acordo com Galas (2006) um solo compactado torna-se um solo mais denso, diminuindo os macro-poros e, consequentemente, a permeabilidade, deixando o solo susceptível à erosão superficial. Contudo, a intensidade da erosão varia de acordo com outros fatores como a intensidade da chuva, a topografia, entre outros.

Outro fator que geralmente está associado à compactação das áreas de pastagens é o pisoteio de animais. Santos et. al., (2010), diagnosticaram as alterações nas propriedades físicas e químicas do solo em área de pastagem e de floresta nativa secundária na microrregião do Brejo Paraibano e concluíram que o pisoteio dos animais favoreceu a compactação da camada superficial, em decorrência do aumento da sua densidade e da redução da porosidade total e da macro porosidade. O material em estudo apresentou disponibilidade reduzida de nutrientes, considerável acidez, valores elevados de Alumínio trocável e menores teores de matéria orgânica do solo influenciado pelos sistemas de uso da terra e pelo aumento da intensidade de uso.

4) Erosão laminar: além das áreas expostas pela formação de estradas e pela morte de parte da pastagem, devido à exposição aos processos intempéricos, a área encontra-se em processo de erosão acelerada do tipo laminar. Esse tipo de erosão não é considerado leve, levando o solo a uma coloração clara e ao descobrimento das raízes das árvores com o seu 


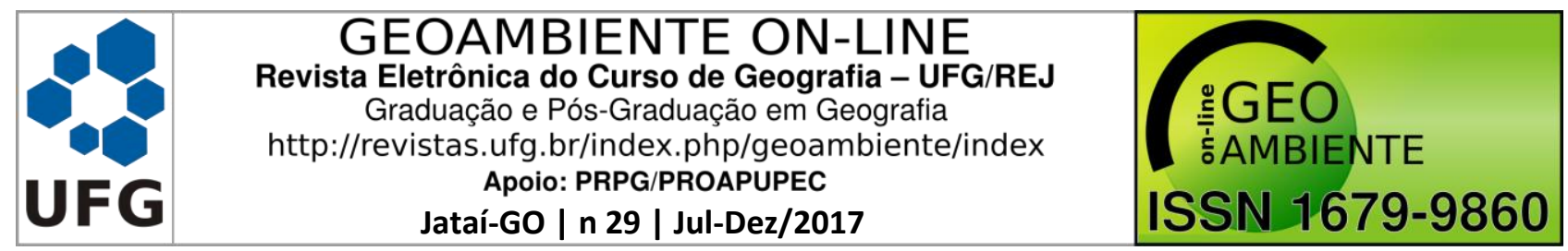

avanço, mas deve ser reparada para que não chegue a um estágio mais avançado(FILHO e FILHO, 2014).

As causas dos impactos encontrados na área de pastagem podem ser desde a escolha incorreta da espécie forrageira, a falta de adubação de manutenção, ausência de controle de pragas e o manejo inadequado da pastagem. Segundo Oliveira et. al. (2013), uma pastagem com má formação inicial, cheia de falhas e invadida pelo mato, com certeza, terá acelerado seu processo de degradação, ou já se inicia degradada.

O Ministério da Agricultura e Abastecimento e a EMBRAPA realizaram um diagnóstico das pastagens nas regiões leste e nordeste do estado de Mato Grosso. Os pesquisadores relataram a morte dessas pastagens, e explicaram que a causa da morte destas é complexa, associada ao estresse hídrico na região, provocado por distúrbios climáticos globais, que podem ser considerados a principal causa da morte de alguns tipos de pastagens, da baixa resistência dessa espécie associada a processos de efeito cumulativo de redução da capacidade de infiltração, de maior escorrimento superficial durante as chuvas, e, portanto, de maior déficit de água de armazenamento nos solos durante a estação da seca (BRASIL, 2000).

\section{Avaliação qualitativa:}

Realizou-se a avaliação qualitativa dos impactos listados no Check-list. Alguns impactos foram considerados diretos como a morte da pastagem e a compactação do solo, pois são os primeiros impactos a se manifestarem logo após as ações degradantes realizadas. Outros foram considerados indiretos, mas não menos nocivos, apenas surgem de forma secundária em relação aos impactos diretos (Tabela 03).

Todos os impactos apesar de negativos tiveram efeitos considerados locais e reversíveis, ou seja, a ação afeta apenas o próprio local e suas imediações e o fator ambiental impactado pode ser recuperado. Além disso, todos os impactos foram considerados permanentes, de curto prazo e local, pois os efeitos dos impactos são logo percebidos e não cessam de se manifestar em um determinado horizonte conhecido, se agravam com o tempo e só atingem a área da fazenda (Tabela 03).

Infere-se então, que existe a possibilidade de mitigação dos danos causados pelo mau manejo da área, porém, devido à característica de serem permanentes necessitam de ações humanas para cessar os efeitos das ações degradantes. Segundo Macedo et.al. (2013) quando o processo de degradação das pastagens tem início, e os impactos são diagnosticados, deve ser planejada uma tomada de ação. Caso a situação seja negligenciada, o processo culminaria 


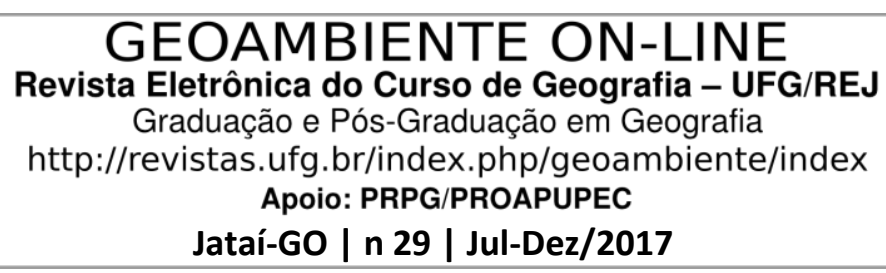

com a ruptura dos recursos naturais; a degradação do solo é representada por alterações em sua estrutura, evidenciada pela compactação, e consequente diminuição das taxas de infiltração ecapacidade de retenção de água, causando erosão e assoreamento de nascentes, lagos e rios.

Tabela 03: Avaliação qualitativa dos impactos encontrados

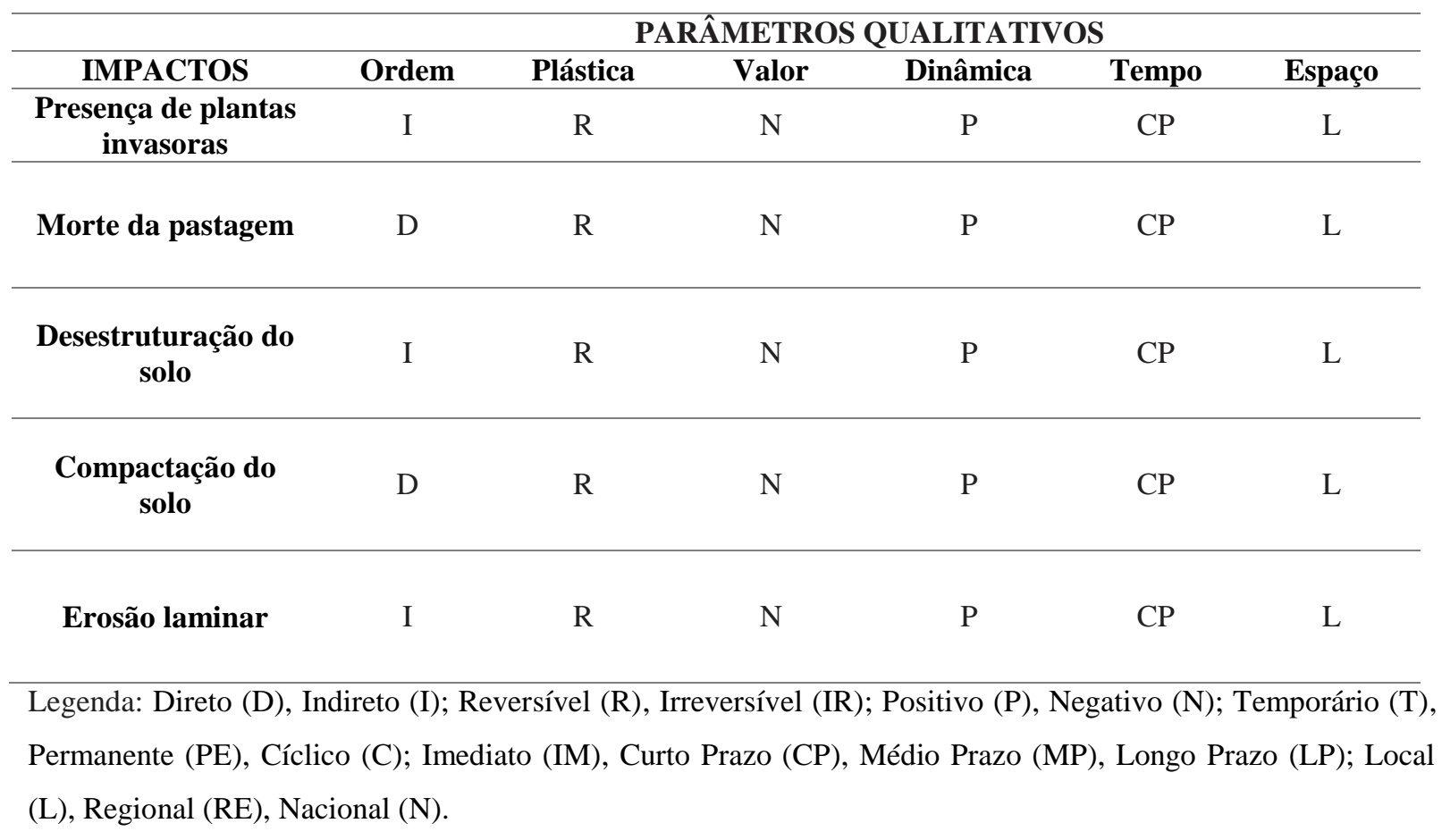

\section{Análise quantitativa:}

A avaliação de todos os parâmetros está apresentada na Tabela 04, assim como o nível de degradação identificado pela somatória das notas dadas aos parâmetros. Observou-se após o diagnóstico ambiental da área, o parâmetro mais afetado foi a cobertura do solo pela pastagem (CS), pois em muitos lugares não havia pastagens, e em outros onde ainda havia, não se apresentava saudável. Logo, foi o parâmetro que apresentou maior nota, 4, que representou um nível "muito ruim" e justificando a intervenção na área, como verificado pela avaliação qualitativa.

O Vigor e qualidade das pastagens (VQ), População de plantas da forrageira (PP) e Nível de erosão (NE) das áreas foram classificados como "ruim", pois observou-se redução da produção de forragem, da qualidade, altura e volume, mesmo nas épocas favoráveis ao crescimento, segundo relato de proprietários rurais. 
Tabela 04.Avaliação quantitativa da degradação da pastagem

\begin{tabular}{ccccccc}
\hline \multicolumn{7}{c}{ Parâmetros Avaliados } \\
VQ & PP & PD & CS & NE & Somatório & NDP \\
\hline 3 & 3 & 2 & 4 & 3 & 15 & FORTE
\end{tabular}

Legenda: VQ - Vigor e qualidade das pastagens, PP - População de plantas da forrageira, PD - Incidência de plantas daninhas, CS - Cobertura do solo pela pastagem e NE - Nível de erosão das áreas.

Apenas o parâmetro Incidência de plantas daninhas (PD) foi considerado "regular", pois a quantidade desse tipo de vegetação ainda não se apresentava dominante em relação à vegetação nativa remanescente e à pastagem.

O somatório das notas foi 15, se enquadrando no nível Forte de degradação (=14 - <17), denotando que a área se encontra degradada e que necessita de intervenção para recuperação. Uma pastagem pode ser considerada degradada dentro de um universo relativamente amplo de condições. Os extremos dessas condições são conceitualmente denominados "degradação agrícola" e "degradação biológica" (DIAS-FILHO, 2014). Pastagens no nível Forte representam a degradação agrícola, enquanto a degradação biológica é representada pelas pastagens no nível Muito Forte. Na degradação agrícola, há um aumento na proporção de plantas daninhas na pastagem, diminuindo gradualmente a capacidade de suporte.

Em um diagnóstico ambiental do nível de degradação da pastagem realizado por FREITAS et. al. (2016) no estado do Tocantins, observou-se que três propriedades analisadas não possuíam pastagens saudáveis e sim apresentavam algum nível de degradação. $\mathrm{Na}$ fazenda que apresentava grau mais Baixo de degradação, havia práticas de manejo da pastagem, enquanto na fazenda de grau mais elevado não havia práticas de manejo da pastagem, demonstrando a importância de práticas de manejo para o vigor da pastagem.

Miranda et. al. (2012) observaram em uma propriedade rural em Campo Grande-MS, que $20,37 \%$ da área de pastagem se apresentavam em estado avançado de degradação e $37,27 \%$ em estado moderado de degradação.Oliveira et. al. (2013), ao analisarem uma pastagem no município de Alterosa, MG, observaram alto grau de degradação, sendo necessária uma rápida intervenção para controle dos processos erosivos (laminar e a voçoroca). Além do controle físico do processo erosivo, outras técnicas deveriam ser aplicadas para conter o processo de degradação da pastagem, tais como, o controle de plantas daninhas, o manejo da pastagem e a reconstrução da fertilidade do solo. 


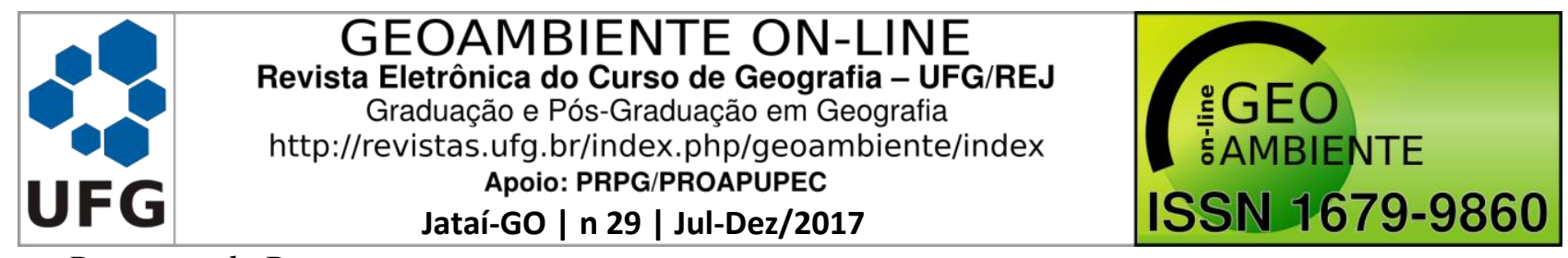

Proposta de Recuperação

Uma das maneiras de mitigar a maior parte dos impactos negativos causados em áreas degradadas, pela atividade agropecuária, ou por outros usos do solo, é o estabelecimento de uma cobertura vegetal perene sobre o local alterado através de Sistemas Agroflorestais. Segundo Alves (2009) a principal vantagem desse sistema em comparação aos sistemas convencionais de uso do solo e restauração ambiental é o aproveitamento mais eficiente dos recursos naturais pela otimização do uso da energia solar, pela reciclagem de nutrientes, pela manutenção da umidade do solo e pela proteção do solo contra a erosão e a lixiviação. $\mathrm{O}$ resultado é um sistema potencialmente mais produtivo e sustentável.

A Tabela 5 demonstra a importância dos SAFs na função de proteção contra perda do solo por erosão. Os dados são provenientes de quatro tipos de cobertura do solo durante a exploração da terra (sem cobertura, cultivo intensivo - mandioca e milho, cultivos perenes SAFs - e floresta nativa) em um Ultisol com $7 \%$ de declividade na Costa do Marfim. Observa-se que a perda de solo nos cultivos perenes é baixa e praticamente igual à floresta nativa (Tabela 5) (BRASIL, s/d).

Tabela 05. Perdas de solo por erosão em Ultisol com 7\% de declividade na Costa do Marfim.

\begin{tabular}{cc} 
Cobertura & Erosão $(\mathbf{t} / \mathbf{h a} / \mathbf{a n o})$ \\
\hline Solo exposto (sem vegetação) & 125 \\
\hline Cultivo de milho & 92 \\
\hline Cultivo de mandioca & 32 \\
\hline Cultivos perennes* (SAFs) & 0,3 \\
\hline Floresta nativa & 0,1 \\
\hline Fonte: Ollagnier et al. (1978) &
\end{tabular}

A escolha das espécies para compor um SAF está diretamente relacionada com o tipo de manejo do sistema e sua função. Na recuperação de áreas degradadas, as espécies devem apresentar características intrínsecas às áreas a serem recuperadas. Por exemplo, no cerrado, as espécies selecionadas devem apresentar capacidade de enraizamento profundo, resistência a longos períodos de déficit hídrico e ser pouco exigente em nutrientes. Em geral, é importante o uso de espécies de rápido crescimento, capazes de depositar matéria orgânica no solo e reciclar nutrientes (TORRES, 2015). As leguminosas arbóreas surgem como boa alternativa, pois possuem vasto sistema radicular, apresentam potencial para nodulação e fixação simbiótica de nitrogênio atmosférico e são de múltiplos usos.

Não existe um modelo-padrão para formar agroflorestas. Trata-se de um princípio de condução das áreas rurais, mas os desenhos mudam de acordo com a destinação, a função da 

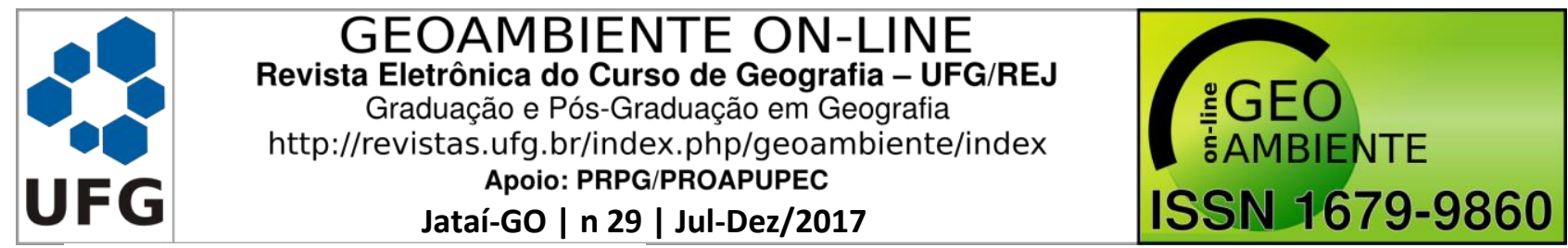

área e as condições encontradas. Deve-se levar em consideração o clima da região e as diferenças microclimáticas, pois dentro de uma mesma sub-bacia existem diferentes microambientes devido a fatores como a topografia, que se relaciona com os tipos de solo, a retenção de umidade, a disponibilidade de nutrientes e de matéria orgânica(ALVES, 2009).

Em trabalho realizado por Bernardes (2008), utilizou-se o plantio de milho, feijão e mandioca, em área no quarto ciclo da cultura de eucalipto, aproximadamente 28 anos, numa região de baixa aptidão agrícola que apresentava solos de tabuleiros costeiros, sem irrigação e sem controle de pragas e doenças. As plantas perto do eucalipto apresentaram produtividade muito superior quando comparadas ao restante da parcela. Os resultados da área de observação implantada indicaram a complementaridade do uso do ambiente disponível (solo e clima) pelos cultivos envolvidos (eucalipto, feijão, milho e mandioca).

Outra opção é a utilização da cultura de eucalipto como quebra-vento de cafeeiro, realizaram-se dois experimentos: o primeiro com duas linhas de café, intercaladas entrelinhas simples de árvores de eucalipto; e o segundo, com 11 linhas intercalares de cafeeiros. No segundo experimento foram intercaladas cinco linhas de café entre duas linhas de eucalipto em uma área de monocultivo de café(BERNARDES, 2008).

Não só o eucalipto, mas outras espécies arbóreas vêm demonstrando ser uma boa escolha na aplicação de Sistemas Agroflorestais, como: mogno, castanha-do-brasil e teca. Santos (2000)observou que além de economicamente viável, esses sistemas são benéficos para recuperar áreas degradadas. O modelo multiestrato, com introdução de diversas espécies arbóreas frutíferas perenes (mogno, castanha-do-brasil e teca) e semiperenes (araçá-boi, jenipapo, acerola e maracujá) e com cultivo de arroz no primeiro ano, juntamente com cupuaçu, apresentou maior desempenho pelo valor comercial das espécies adotadas.

Em um estudo realizado por Silva et al. (2010), um dos sistemas agroflorestais testados foi o de eucalipto (Eucaliptusgrandis, E. urophylla, híbrido urograndis ou Corimbacitriodora) associado à gramínea (Brachiariabrizantha) e à leguminosa (Calopogoniummuconoides), tendo como objetivo a criação de gado para pecuária leiteira. $\mathrm{O}$ autor observou que o plantio das espécies para a formação da pastagem pode ser simultâneo ao plantio da espécie florestal.

Mesclar produtos madeireiros e não madeireiros pode ser a melhor escolha para o sucesso do empreendimento, pois proporciona fluxo de caixa maior ao agricultor, flexibilidade de comercialização e otimização de mão-de-obra. A produção de culturas em 


\section{GEOAMBIENTE ON-LINE \\ Revista Eletrônica do Curso de Geografia - UFG/REJ \\ Graduação e Pós-Graduação em Geografia \\ http://revistas.ufg.br/index.php/geoambiente/index \\ Apoio: PRPG/PROAPUPEC \\ Jataí-GO | n 29 | Jul-Dez/2017}

SAFs pode superar o monocultivo em termos de produtividade, se for adotado manejo adequado.

\section{CONCLUSÕES}

- Através do diagnóstico ambiental observou-se que a propriedade analisada apresenta impactos ambientais, como: morte da pastagem, presença de plantas invasoras, compactação do solo e erosão laminar.

- Os impactos foram classificados como: negativos, locais, diretos, de curto prazo e permanentes. A análise qualitativa dos impactos demonstrou o caráter reversível dos impactos, confirmado pela análise quantitativa, a qual revelou que a área se encontra em um estado forte de degradação, necessitando de intervenção para reversão do quadro.

- O SAF é um sistema que se encaixa na área. De acordo com a literatura, mesclar espécies arbóreas (eucalipto, mogno e cedro) com espécies não arbóreas é o tipo de modelo que pode gerar maiores ganhos econômicos e ambientais.

\section{REFERÊNCIAS BIBLIOGRÁFICAS}

ALVES, L. M. Sistemas Agroflorestais (SAF's) na restauração de ambientes degradados. Material didático. Junho de 2009. Disponível em <http://www.ufjf.br/ecologia/files/2009/11/Est\%C3\%A1gio-Doc\%C3\%AAncia

LUCIANA.pdf>. Acesso: 28/04/2016

BERNARDES, M. S. Sistemas Agroflorestais. In: XXXIII SECITAP. Jaboticabal: UNESP. (Palestra). 2008.

BRASIL, Resolução CONAMA No 001, de 23 de janeiro de 1986.

BRASIL, Comissão executiva do plano da lavoura cacaueira - CEPLAC. Sistemas agroflorestais como uso sustentável dos solos: conceito e classificação. s/d. Disponível em <http://www.ceplac.gov.br/radar/semfaz/conceiroeclassificacao.htm>. Acesso em: 28 abr. 2016.

BRASIL, Ministério da Agricultura, Pecuária e Abastecimento. Plano Setorial de Mitigação e de Adaptação às Mudanças Climáticas para a Consolidação de uma Economia de Baixa Emissão de Carbono na Agricultura. Brasília: MAPA/ACS. 173 p. 2012.

BRASIL, Ministério da Agricultura e Abastecimento e a EMBRAPA. Diagnóstico de morte de pastagens nas regiões leste e nordeste do estado de mato grosso. Campo Grande, MS 2000. 


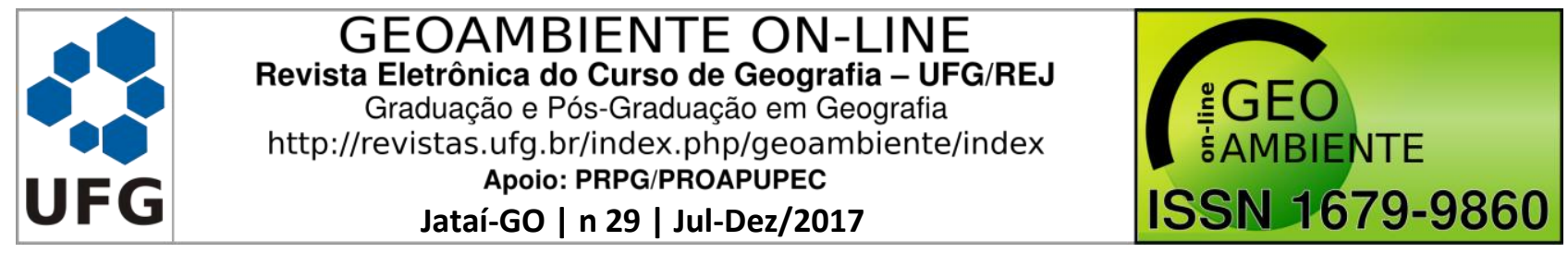

DIAS-FILHO , M. B. Diagnóstico das Pastagens no Brasil EMBRAPA Maio, 2014.

Disponível em

<https://www.infoteca.cnptia.embrapa.br/bitstream/doc/986147/1/DOC402.pdf>. Acesso em: 28 abr. 2016.

DIAS-FILHO, M. B. Degradação de pastagens: processos, causas e estratégias de recuperação. 4. ed. rev., atual. eampl. Belém, PA, Ed. Do Autor 2011. Disponível em < http://www.diasfilho.com.br/Livro/Degrad_Past_4a_ed_Moacyr_Dias-Filho.pdf $>$. Acesso em: 28 abr. 2016.

FILHO , G. S. de A.; FILHO, J. T. A importância da diferenciação dos processos erosivos lineares dos tipos ravina e boçoroca. XII Simpósio de recursos hídricos do nordeste a importância da diferenciação dos processos erosivos lineares dos tipos ravina e boçoroca.

Natal/ RN. 2014. $\quad$ Disponível em

<http://www.abrh.org.br/xiisrhn/anais/papers/PAP018502.pdf>. Acesso em: 28 abr. 2016.

FREITAS, G. A. de.; BENDITO, B. P. C.; SANTOS, A. C. M. dos; SOUSA, P. A. de.Diagnóstico ambiental de áreas de pastagens degradadas no município de Gurupi-TO .

Revista Biota Amazonica. Macapá, v. 6, n. 1, p. 10-15, 2016. DOI: http://dx.doi.org/10.18561/2179-5746/biotaamazonia.v6n1p10-15. Disponível em < https://periodicos.unifap.br/index.php/biota/article/view/1287>. Acesso em: 28 abr. 2016.

GALAS, N. D. Uso de vegetação par contenção e combate a erosão em taludes. 2006. 64 f. Monografia (Especialização) - Curso de Engenharia Civil, Universidade Anhembi Morumbi, São Paulo, 2006. Disponível em: <http://engenharia.anhembi.br/tcc-06/civil55.pdf>. Acesso em: 28 abr. 2016.

LEOPOLD, L.B.; CLARKE F. E.; HANSHAW, B. B.; BALSHEY, J.R.. A procedure for evaluating environmental impact. Washington: U. S. Geological Survey. 13p. (circular 645). 1971.

MACEDO, M.C.M. Recuperação de áreas degradadas: pastagens e cultivos intensivos. In: Congresso Brasileiro de Ciências do Solo, 7, Goiânia. Anais... Goiânia: SBSC, 1993. p.7172. 1993.

MACEDO, M.C.M.; ZIMMER, A.H. Sistema pasto-lavoura e seus efeitos na produtividade agropecuária. In Favoretto, V.; Rodrigues, L.R.A.; Reis, R.A. (eds.). SIMPÓSIO SOBRE ECOSSISTEMAS DE PASTAGENS, 2, Jaboticabal. Anais... Jaboticabal: FUNEP, UNESP, 1993. p.216-245. 1993. 
MACEDO, M. C. M.; ZIMMER, A. H.; KICHEL, A. N.; ALMEIDA, R. G. de; ARAUJO, A. R. de. Degradação de pastagens, alternativas de recuperação e renovação, e formas de mitigação. Encontro de adubação de pastagens da scot consultoria - tec - fértil, 1., 2013, Ribeirão Preto, SP. Anais... Bebedouro: Scot Consultoria, 2013. p. 158-181. Disponível em <http://www.alice.cnptia.embrapa.br/handle/doc/976514>. Acesso em: 28 abr. 2016.

MIRANDA, C. de S.; LIMA, D. L. Diagnóstico dos níveis de degradação das pastagens com o uso geotecnologias Terceiro seminário de gestão ambiental na agropecuária. Bento Gonçalves - RS, Brasil, 25 a 27 de Abril de 2012. Disponível em < http://www.proamb.com.br/downloads/p506xt.pdf>. Acesso em: 28 abr. 2016.

NASCIMENTO JÚNIOR, D. do; QUEIROZ, D. S.; SANTOS, M. V. F. dos. Degradação de pastagens, critérios para avaliação. In: Simpósio sobre manejo da pastagem, 11. Piracicaba. Anais... Piracicaba: FEALQ. p. 107-151. 1994.

OLLAGNIER, M.; LAUZEREL, A.; OLIVIN, J.; OCHS, R. Evolution des sols sons palmeraie aprè defrichement des forêt. Olleagineaux 33:537-547. 1998.

OLIVEIRA, T. C.; PEREIRA, D. N.; T. E. de BRITO, AGOSTINI, J. A. F.; LIMA, P. F.; SILVA, A. V.; SANTOS, C. S.; BREGAGNOLI, M..Diagnóstico e recuperação de áreas de pastagens degradadas. Revista Agrogeoambiental, Pouso Alegre, Edição Especial n. 1, p. 49-53, ago. 2013. DOI: http://dx.doi.org/10.18406/2316-1817v1n12013578. Disponível em < https://agrogeoambiental.ifsuldeminas.edu.br/index.php/Agrogeoambiental/article/view/578>. Acesso em: 28 abr. 2016.

PERON, A. J.; EVANGELISTA, A. R. Degradação de pastagens em regiões de cerrado. Revista Ciência e Agrotecnologia. v. 28 n 23.p; 655-661. 2004. Doi: http://dx.doi.org/10.1590/S1413-70542004000300023 . Disponível em < http://www.scielo.br/pdf/cagro/v28n3/23.pdf> Acesso em: 28 abr. 2016.

RODOVALHO, N. L.; Análise comparativa da viabilidade econômica e ambiental dos manejos do capim-gordura (Melinisminutiflora) em unidades de conservação. 2012. 64 f. TCC (Graduação) - Curso de Gestão Ambiental, Universidade de Brasília, Brasília, 2012.

RODRIGUES, B. R. Agricultura de baixo carbono (abc). 2014. 27 f. TCC (Graduação) Curso de Agronomia, Uni- Anhanguera - Centro Universitário de Goiás, Goiânia, 2014. Disponível em: $<$ http://pos.anhanguera.edu.br/wpcontent/uploads/2016/03/AGRICULTURA-DE-BAIXO-CARBONO-ABC.pdf>. Acesso em: 28 abr. 2016. 


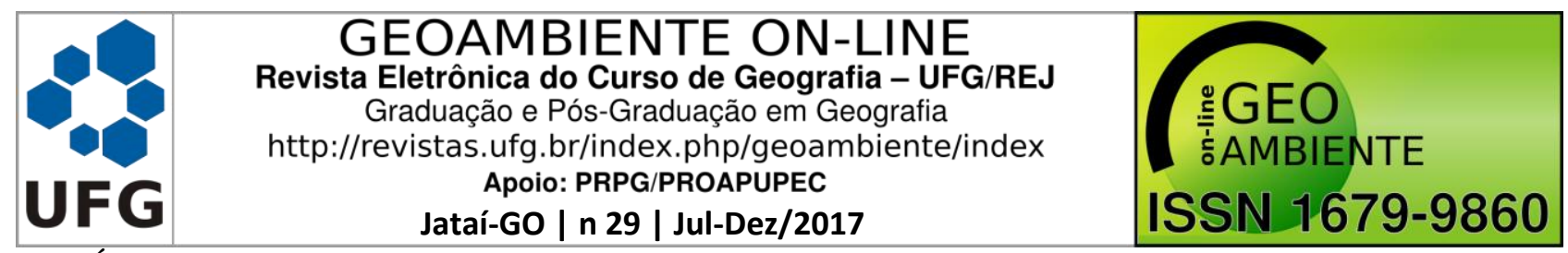

SÁNCHEZ, E. L.; Avaliação de Impacto Ambiental conceitos e métodos. $2^{a}$ edição. Editora Oficina de textos. 584 p. 2013.

SANTOS, J. T. dos; ANDRADE, A. P. de; SILVA, I. de F. da; SILVA, D. S. da; SANTOS, E. M.; SILVA, A. P. G. da. Atributos físicos e químicos do solo de Áreas sob Pastejo na Micro Região do Brejo Paraibano; Ciência Rural, Santa Maria, 2010 CR-2625. http://dx.doi.org/10.1590/S0103-84782010001200008. Disponível em: <http://www.scielo.br/pdf/cr/v40n12/a793cr2625.pdf>. Acesso em: 28 abr. 2016.

SANTOS, M. J. C. Avaliação econômica de quatro modelos agroflorestais em áreas degradadas por pastagens na Amazônia ocidental. (Dissertação de mestrado). Piracicaba: ESALQ-USP, 75p. 2000.

SILVA, J. J. da; DANIEL, O.; CREMON, T.; NOGUEIRA, I. M. B. Modelos de sistemas agroflorestais para a mesorregião sudoeste de Mato Grosso do Sul. Revista Extensão Rural, DEAER/PPGExR - CCR - UFSM, Ano XVII, n 19, Jan - Jun de 2010. Disponível em: <https://periodicos.ufsm.br/extensaorural/article/view/5514>. Acesso em: 28 abr. 2016 TORRES, C. M. M. E.. Estocagem de carbono e inventário de gases de efeito estufa em sistemas agroflorestais, em viçosa, mg. 2015. 97 f. Tese (Doutorado) - Curso de Ciência Florestal, Universidade Federal de Viçosa, Viçosa Minas Gerais - Brasil, 2015. Disponível em:<http://locus.ufv.br/bitstream/handle/123456789/6844/textocompleto.pdf?sequence=1\&is Allowed=y >. Acesso em: 28 abr. 2016.

ZEBU, Centro de Referência da Pecuária Brasileira. Manejo e Recuperação de Pastagens. 2015. Disponível em <http://www.crpbz.org.br/Home/Conteudo/13879-Manejo-erecuperacao-de-pastagens>. Acesso em: 28 abr. 2016. 